Published in "Theoretical issues in ergonomics science 10(6) : 489-509, 2009"

which should be cited to refer to this work.

\title{
Designing training for process control simulators: a review of empirical findings and current practices
}

\author{
Annette Kluge ${ }^{\mathrm{a} *}$, Jürgen Sauer ${ }^{\mathrm{b}}$, Kerstin Schüler ${ }^{\mathrm{a}}$ and Dina Burkolter ${ }^{\mathrm{a}}$ \\ ${ }^{a}$ Research Institute for Organizational Psychology, University of St Gallen, Varnbüelstrasse 19, \\ CH-9000 St Gallen, Switzerland; ${ }^{b}$ Department of Psychology, University of Fribourg, Rue de \\ Faucigny 2, CH-1700 Fribourg, Switzerland
}

(Received 28 March 2007; final version received 13 January 2008)

\begin{abstract}
Although simulators have been widely used as training environments in different industries (e.g. oil and nuclear power), there is little rigorous empirical work evaluating the effectiveness of the training methods employed. This article examines the use of simulator training in process control environments. The results of an exploratory field study are reported and the current practices of simulator training are described. The study revealed that simulator training varied considerably across organisations, often with little theoretical or empirical work to guide training design. To evaluate the utility and effectiveness of different methods of simulator training in process control environments, the article also presents a literature review of the research on laboratory- and field-based training. Several training methods are identified as having particular potential for temporal and adaptive transfer and are to be empirically tested in future studies.
\end{abstract}

Keywords: process control; simulator; training requirement analysis; training methods; temporal transfer; adaptive transfer

\section{Training requirements for high-risk environments}

Nuclear power plants, coal-fired power plants and oil refineries are technical systems that require an organisational structure typically referred to as high-risk environments or highreliability organisations (Weick and Sutcliffe 2003). This type of organisation has to operate at a very high level of reliability because system breakdowns of the plant may severely damage the environment or affect people's lives and health (e.g. the Three Mile Island accident in 1979 and the explosion in an oil refinery near Houston, Texas, in 2005). To achieve such high reliability, organisations operating in high-risk environments expect that their own organisational sub-systems might fail and that their employees are susceptible to human errors. These organisations therefore go to great lengths to avoid failures and errors, preparing their workers for the worst case in order to minimise the impact of failures.

Changing the role of individual operators is only one lever to increase reliability in high-risk environments (Rasmussen 1997, Vicente 2006). Regular training is one such operator-centred approach to providing the preconditions for high reliability in high-risk environments. Training for plant operators often comes in the form of simulator training. 
Simulators can be used for training without disrupting normal system operations and can replace on-the-job training in the field because unusual events can be simulated with higher frequency (Flexman and Stark 1987). Simulator training is viewed as safer, more economical and more convenient than training on the real system. Simulators are used to demonstrate physical, chemical or biological aspects of the plant's behaviour. Furthermore, they are employed to practise the use of checklists or safety procedures and to test and evaluate the trainees' learning progress or competence.

Nevertheless, the use of simulators for such purposes raises questions. Despite some evidence for the effectiveness of simulator training, the reasons why simulators are so effective remain unclear (Salas et al. 2006). According to Salas et al., simulators are often used without "much consideration of what has been learned about cognition, training design or effectiveness' (p. 486). There are three particular misperceptions of simulator use in training (Salas et al. 1998): (1) simulation is all that is needed; (2) the higher the fidelity level, the better the simulation is; (3) if the trainees like the simulation, it is good.

With regard to the last point, Salas et al. (2006) have commented that the confidence in simulators might be due to the fact that most research on their effectiveness has been based on the subjective evaluation of trainees rather than on objective performance data. Salas et al. have therefore proposed a systematic evaluation of training with simulators to link technology, training and performance.

The goal of this paper is to propose instructional techniques suitable for simulator training. To achieve this goal, the research literature has been reviewed and evaluated with regard to training and learning principles relevant for simulator training in process control and analogue work environments.

\section{Simulator training and training simulators}

\subsection{History of training simulators}

The use of simulators for training purposes has a long tradition. For example, in military aviation (Heintzman 1984, Flexman and Stark 1987) the first aircraft simulator was designed in 1929. For process control, the first use of nuclear power plant simulators dates back to the years 1957 and 1959 (Amico and Clymer 1984, Waibel and Benkert 1995). Both simulators were developed in the United States to train operators and included a replication of the control rooms. In the late 1960s and the early 1970s, European and Asian countries (e.g. France, Sweden, Germany, Japan and the Soviet Union) put similar training in use. In most countries, fossil-fuel power plants did not use simulators until the 1970s (Amico and Clymer 1984). Computer-based simulators of chemical processes emerged from 1960 to 1963 in the leading companies of the industry (such as DuPont, Amoco, Esso, Dow and US Steel). Oil and gas well-drilling simulators appeared in the late 1970s for training rig personnel. Simulators, especially process control simulators, have thus been in use for many decades for training purposes.

\subsection{Prevalence of simulator training in process control: an exploratory field study}

Little is known about the current use and design of simulator training in process control. Therefore, an exploratory survey was conducted in winter 2005 and spring 2006 to document and analyse the use of simulators for process control tasks in industrial settings and related commercial application areas. In total, 14 experts from 12 organisations from Germany, Switzerland and Austria were interviewed in a semi-structured format. The goal 
of the survey was to gain an overview of current training practices in process control simulators. In a first step, the survey focused on these countries for reasons of accessibility. An important question naturally concerns the extent to which the process control environments examined in the survey are representative. Whenever possible, this paper will refer to literature-based findings from other countries.

In addition to these interview data, the analysis included training material, documents and brochures provided by instructors and human resource specialists. The results of this exploratory survey are summarised in Table 1 .

\subsubsection{Simulator types}

Table 1 shows that the industrial plants with the highest risks, such as nuclear power plants, mainly use full-scope simulators, which incorporate a detailed model of the system with which the operator works in the actual control room. Such simulators also include a replica control-room operating console. They usually refer to plants, replicating as many aspects of the workplace as possible and duplicating the actual control-room environment (International Atomic Energy Agency 1996, p. 39). Some training objectives associated with trouble shooting (fault diagnosis of critical subsystems) can be achieved only through full-scope simulation (International Atomic Energy Agency 1996, p. 39). A full-scope simulator setting needs additional classrooms for theoretical instruction and instructor stations from which the exercises are controlled and observed (see Figure 1).

Industrial plants with relatively low risks, such as conventional power plants and oil refineries, also use generic simulators (see Figure 2). Generic simulators include basicprinciples and part-task simulators. Basic-principles simulators illustrate general concepts, demonstrating and displaying the fundamental physical process of a plant. The main goal is 'to help trainees to understand fundamental physical processes, basic operations of complex systems, and the overall operation of a plant' (International Atomic Energy Agency 1996, p. 2). A part-task simulator incorporates detailed modelling of a reference plant but only of some portions of systems, 'enabling a trainee to be trained specifically on only parts of a job or task' (p. 2).

According to the German PowerTech Training Centre, the variety of Germany's approximately 200 fossil-fuel power plants makes it impossible to have a full-scope simulator for each plant. Instead, they own five generic simulators, which replicate standard operations of a power plant.

Different types of simulators (notably generic and full-scope simulators) are also in use in Russia, US, UK, France and Japan to meet specific training objectives (International Atomic Energy Agency 2004).

\subsubsection{Target groups}

In most oil refineries, control-room operators with 7 to 10 years of work experience in plant operation typically receive 3 to 4 days per year. Two refineries train their apprentices 1 day per year during their 3 year vocational training. In nuclear power plants, operators are trained in teams.

\subsubsection{Training courses and objectives}

The survey revealed two types of training: basic courses normally lasting several days or some weeks to train novices in the control room; and regular follow-up training 


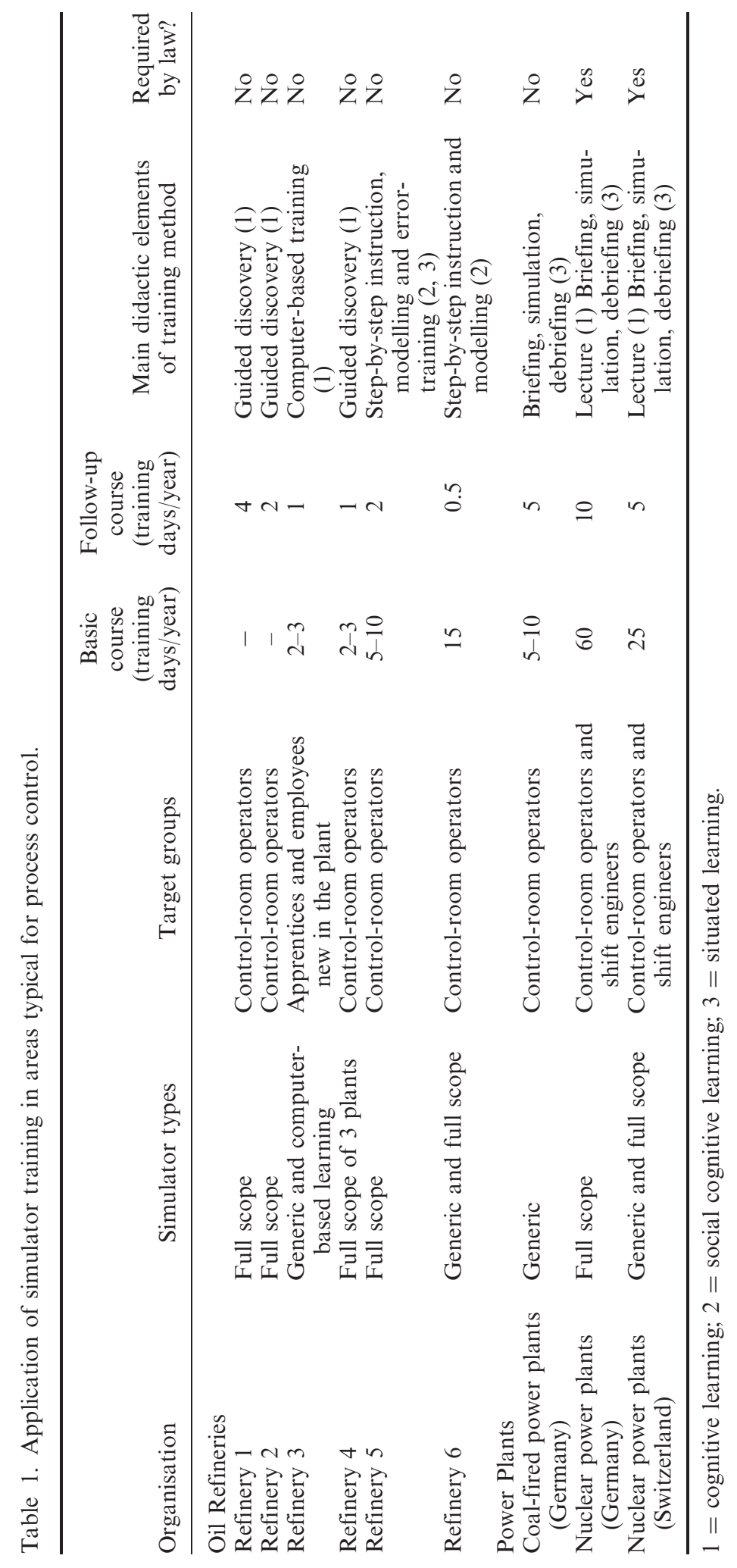




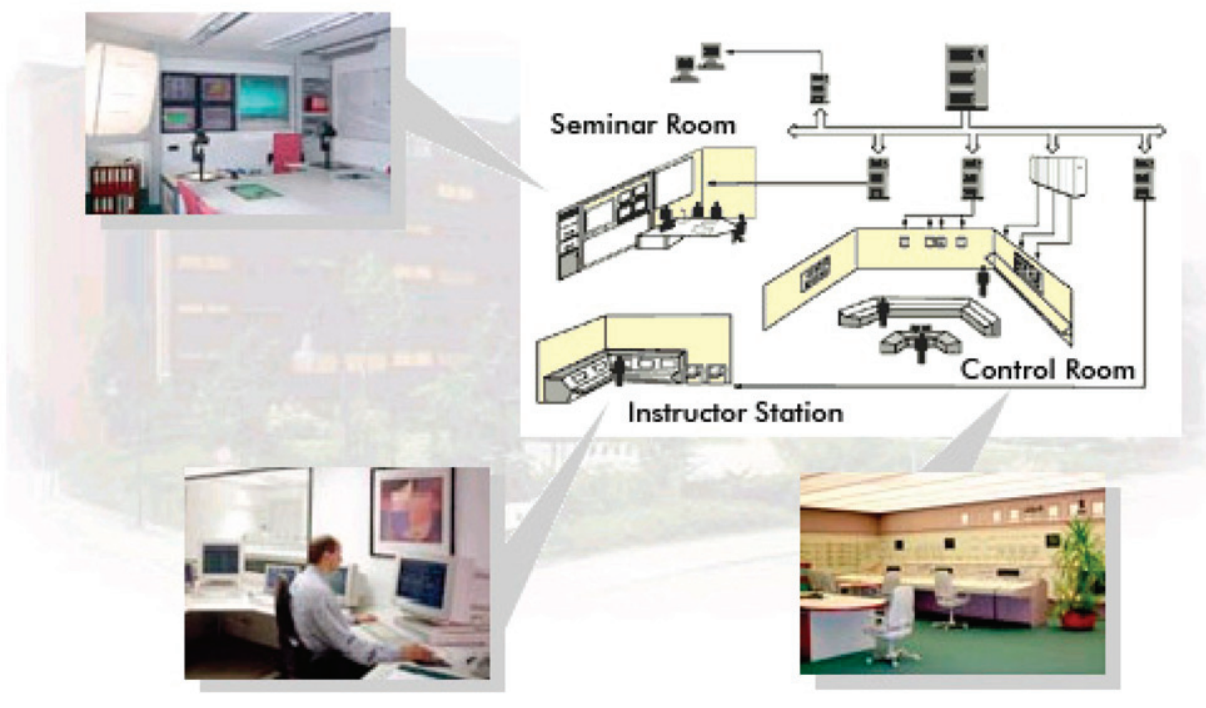

Figure 1. Simulator of a nuclear power plant (Source: GfS mbH).

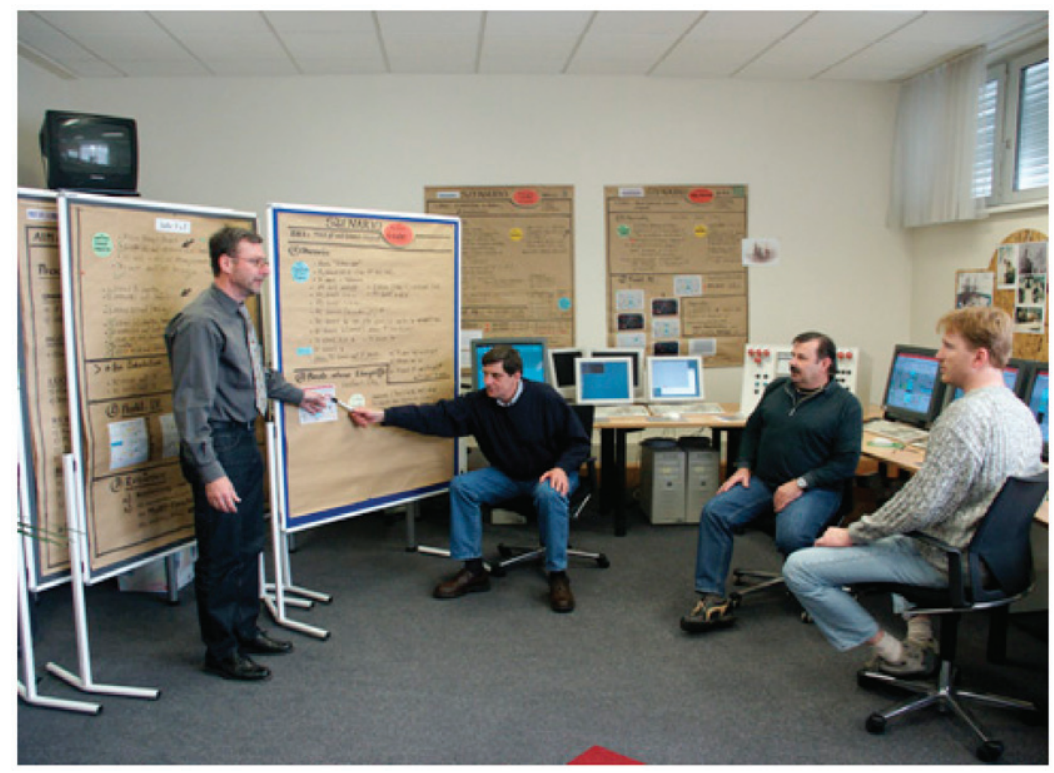

Figure 2. Simulator room with three generic simulators and pin boards for theoretical instructions at OMV (Austrian mineral oil authority), Vienna.

(including malfunction training) for experienced control-room operators. Learning objectives of the basic courses cover the general understanding of system functionality, start-up and shut-down procedures, efficient plant operation, the acquisition of basic declarative (factual or conceptual knowledge, 'knowing that') and procedural knowledge (knowledge of rules, 'knowing how') for normal plant operation and the use of checklists 
and standardised procedures. Learning objectives of the follow-up courses cover the automatisation of procedural knowledge and use of checklists, maintenance of skills and the elaboration of the participant's understanding. The training in trouble shooting as part of the follow-up courses focuses on consolidation of procedural knowledge, the use of checklists in emergency situations, and the practice of unusual situations. This distinction between basic and follow-up training has also been found in nuclear power plants in France, Russia, Japan and US (International Atomic Energy Agency 2004).

\subsubsection{Training methods}

The interviews revealed considerable differences in training methods between process control application areas and across countries. Identified training methods were categorised into three major learning theories: cognitive; situated; social-cognitive (also known as behaviour modelling).

In cognitive learning theory it is assumed that learning involves the formation of mental associations not necessarily reflected in overt behaviour changes and that learning is a process of relating new information to previously learned information (e.g. Cobb and Bowers 1999). This learning theory plays a role in the theoretical training provided by German and Swiss nuclear power plants. Some German refineries, too, offer basic courses that train operators according to the cognitive training method. Cognitive training methods are also made use of in some training centres for nuclear power in China and the US (International Atomic Energy Agency 2004).

In situated learning, students participate actively in problem-solving and critical thinking pertaining to a learning activity that they find relevant and engaging. The assumption in situated learning is that most learning is context-dependent. Cognitive experiences are therefore situated in authentic activities such as project-based or problembased learning (e.g. Greeno et al. 1993). This training is applied in German and Swiss nuclear power plants and in some follow-up training conducted by fossil-fuel power plants. Situated learning methods are also employed in French process control environments (International Atomic Energy Agency 2004).

Social-cognitive learning theory focuses on how people learn from experts. It encompasses such concepts as observational learning and modelling, imitation and practice and part-task training (Bandura 1986). In most basic courses of this type offered by refineries, trainees learn from observation and imitation. This form of training is also recommended by some US and UK authorities dealing with training issues in nuclear power plants (International Atomic Energy Agency 2004).

\subsubsection{Legal requirements}

The design of simulator training is also influenced by legal requirements in specific industries. Rather strict regulations determine the frequency of simulator training when it comes to nuclear power plants and commercial aviation. Non-compliance is grounds for revoking the licence to operate the plant or fly an airplane. Simulator training in nuclear power plants and commercial aviation is therefore also used as an instrument to assess operator competencies regularly. The Swiss Department for Safety in Nuclear Power Plants stipulates that operators be trained in the use of the simulator. For example, it mandates that basic training for operators must include several weeks of this instruction. But there is no detailed regulation about the frequency and duration of simulator training 
(Frischknecht and Deutschmann 1995). Unlike nuclear installations, conventional power plants and refineries have no such regulations.

\section{Systematic training approach to process control simulator training}

Although there are some general suggestions for how simulator training should be conducted in a nuclear power plant (Schneider 1985, International Atomic Energy Agency 2004), they consist only of broad principles for training and learning that are not specific to simulator training. Therefore, 'more research must be done to verify that simulators being used today will follow the science of learning' (Salas et al. 2006, p. 486). This section unites both aspects - simulators and science of learning - by describing the status quo of training methods in order to derive principles for simulator training. This presentation may help shape a systematic approach to such training. The section begins with a brief analysis of the context, target group and tasks relating to training needs. It draws on the present study's interview data, which serve as a foundation for systematically reviewing training experiments and their results to determine their utility for simulator training.

\subsection{Training requirements based on an analysis of training needs}

Simulator training usually takes place in highly automated high-risk environments. These are very demanding because operators have to carefully evaluate the consequences of their actions based on the conceptual understanding of system functioning before their implementation (Vicente and Rasmussen 1990). In these settings, experience-based on-thejob learning is all but impossible because critical incidents important for that learning are fortunately - very rare. With regard to the target groups of training as outlined above, simulator training can build on the operator's previous work experience. As for the task involved, process control incorporates two main components: (a) monitoring and controlling processes; and (b) detection, location and diagnosis of system faults (and malfunctions) and intervention (Wickens 1992, Vicente et al. 2001, Ormerod and Shepherd 2004). Whereas monitoring mainly requires declarative knowledge, fault diagnosis mainly requires procedural knowledge.

Both skill components must be applied, not only to routine operations but also to situations not previously encountered, a shift that requires adaptive transfer (Ivancic and Hesketh 2000). In that respect, operators have to improvise and quickly adapt to the contingencies of an abnormal event to ensure system safety. Operators must generate an appropriate response based on a conceptual understanding of the system (Vicente and Rasmussen 1990). In most cases, there is no direct temporal transfer, which means that the acquired skills cannot be applied directly after training. Instead, a long retention interval must be considered because of long lay-offs and periods of non-use. Skill loss may even occur when operators work with a system but do not complete certain key tasks for prolonged periods of time (Stammers 1996). In summary, both adaptive and temporal transfers are important issues in training design.

Turning to the analysis of training needs, this paper now evaluates the utility of each training method for the extent to which it considers the work experience of the target group; the training in declarative knowledge, procedural skills or both; and the temporal and adaptive transfer of acquired skills.

The findings from the literature review and the conclusion drawn are summarised in Table 2 and explained in the following section. The suggestions take into account the need 


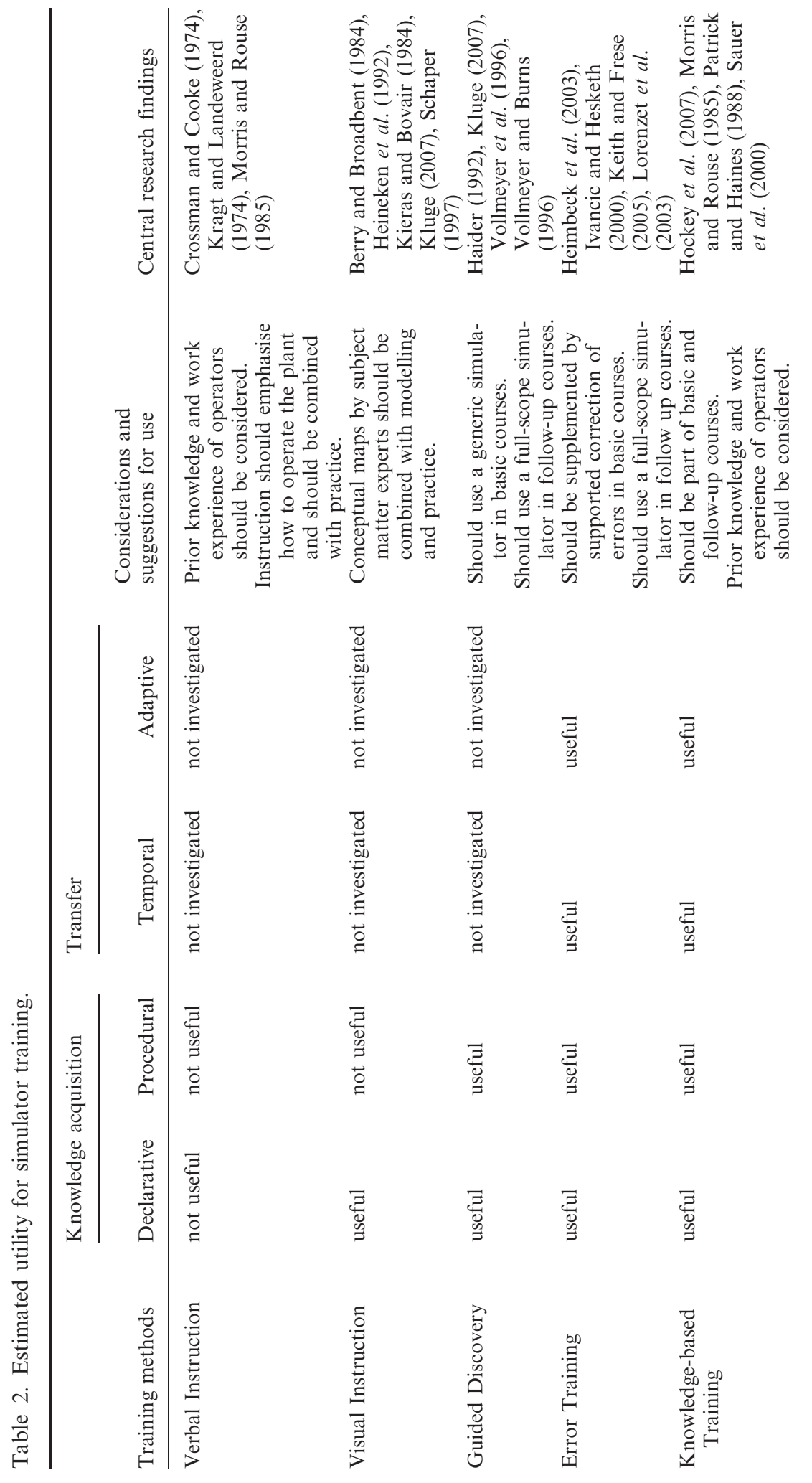




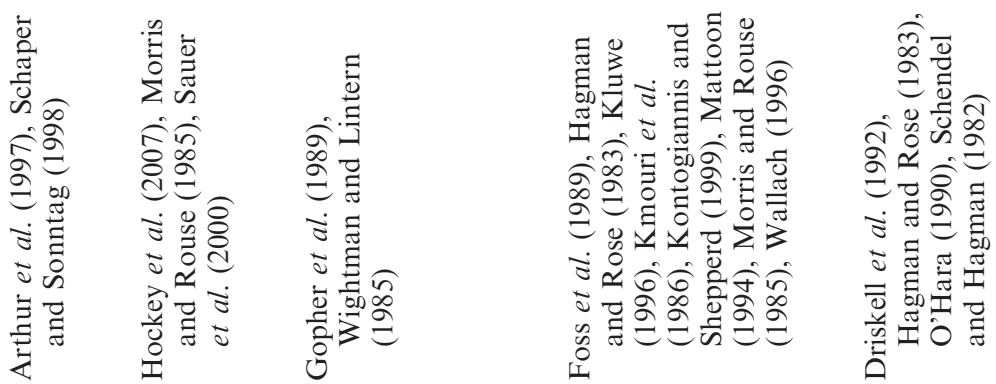

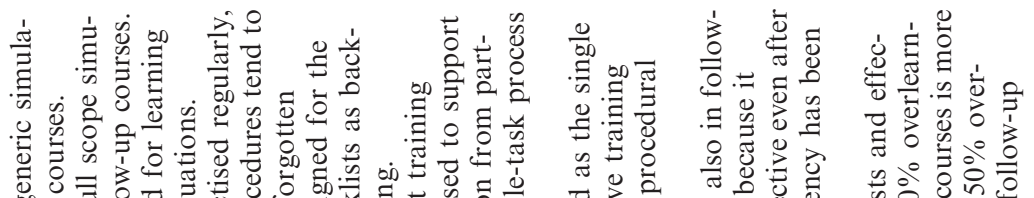

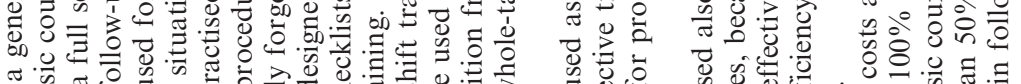

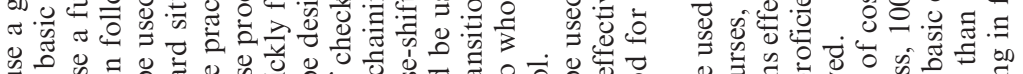

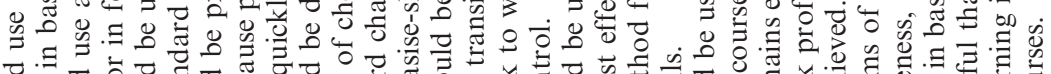

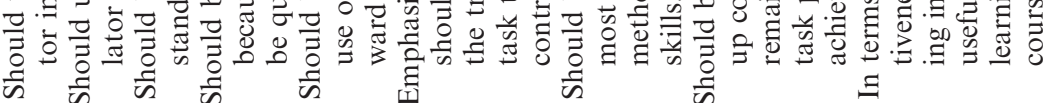
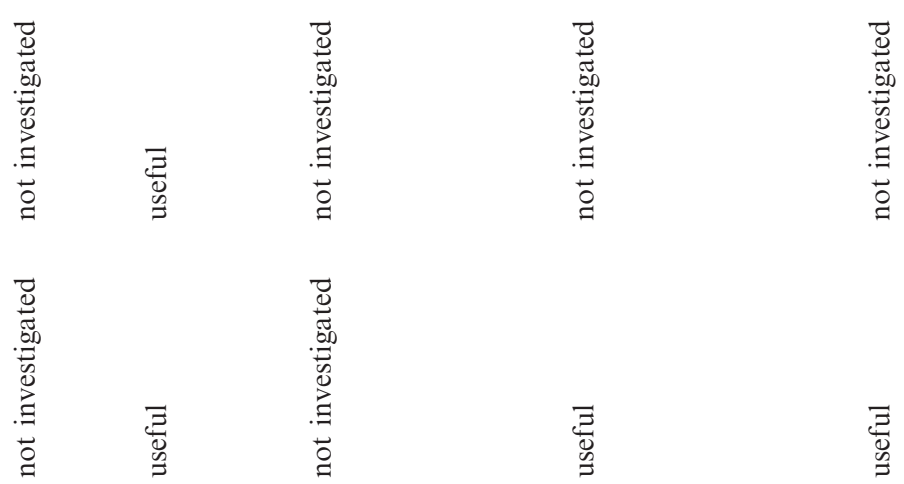

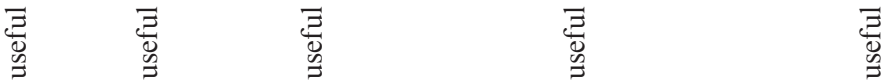

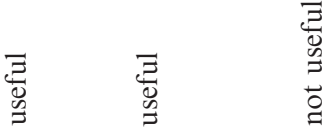
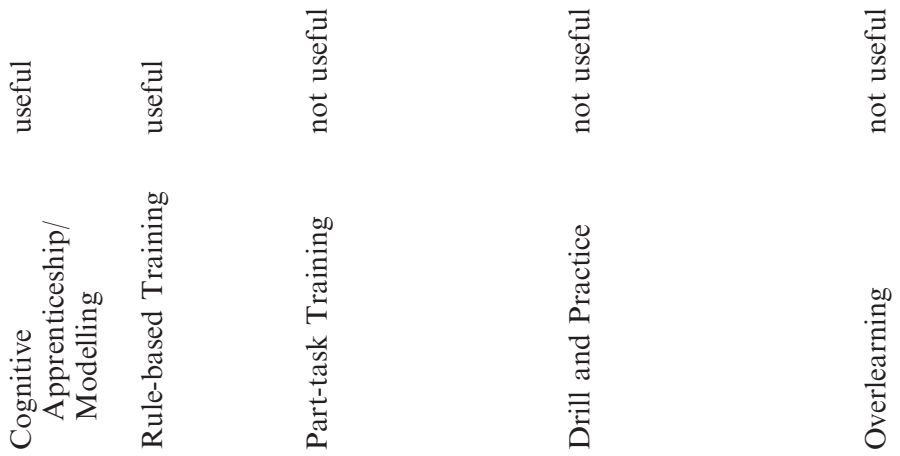
for the acquisition of declarative and procedural knowledge and the need for temporal and adaptive transfer.

\subsection{Training approaches in process control and analogue work environments}

To derive more specific training principles and guidelines, the findings on training research are now reviewed and evaluated in relation to the training in process control tasks. Also included are methods that are not used in process control but in related areas. The training methods are grouped according to the three learning theories presented above: cognitive; situated; social-cognitive. The training methods are briefly described, research evidence is reported and the utility of the training method for simulator training in process control is evaluated.

\subsubsection{Cognitive learning methods}

\subsubsection{Oral instruction.}

Description of method. Morris and Rouse (1985) describe theoretical instruction in terms of oral presentations as a traditional approach in which the trainee receives a detailed explanation of how a system functions and instruction in the theory underlying the system. The trainee is then expected to develop appropriate strategies to manage the system.

Research evidence. In general, the literature review by Morris and Rouse (1985) showed that instruction in theoretical principles was not in itself an effective way to produce competent operators for process control. However, additional guidance on how to use the knowledge (e.g. to generate hypotheses, chunk information or analyse symptoms) was much more efficient. Further work showed that the effectiveness of instruction also depends on the amount of knowledge provided (Crossman and Cooke 1974, Kragt and Landeweerd 1974). For example, elaborate instruction in the chemical processes and full explanations of the equipment by means of process and control diagrams led to performance that was not as high as that after instruction stating the objective of the control task and how to achieve that objective.

Utility for simulator training. Given the goal acquiring declarative and procedural knowledge, it does not appear that detailed and comprehensive theoretical explanations of the principles of how a plant works are effective for monitoring and fault-finding performance. Instead, this literature review suggests that knowledge of how to operate the plant to achieve certain goals can lead to good performance. On the one hand, the trainees already have several years of work experience and therefore may not need a detailed description of the plant's operation. On the other hand, previous knowledge consists mainly of rule-based knowledge that might call for a rather detailed theoretical foundation. The experiments have thus far yielded no information about the temporal and adaptive transfer of skills acquired by theoretical instruction.

\subsubsection{Visual instruction.}

Description of method. Some experiments have used visual presentations instead of verbal instruction. The main forms have been structure diagrams, causal-loop diagrams and 
concept maps. Visual instruction methods have used visual aids to illustrate the relationships between variables of a complex system. In particular, mapping techniques have been recommended for complex domains and procedural structures (Jonassen et al. 1993). Mapping techniques represent knowledge structures through networks of knots (which represent concepts such as persons, objects and incidents) and edges (which represent relations between concepts by means of expressions such as 'is part of' and 'is the cause of').

Research evidence. Training research on several control tasks has shown that structure diagrams increase knowledge about the system but do not improve system control performance (Berry and Broadbent 1984, Kieras and Bovair 1984, Heineken et al. 1992, Kluge 2007). In contrast, in fault-finding training for apprentices the use of mapping techniques together with experts encourages active elaboration, construction and reconstruction of knowledge when complex tasks are involved (Schaper 1997).

Utility for simulator training. With regard to acquiring declarative knowledge, mapping techniques seem to be useful in the hands of experts who make explicit how their knowledge is structured and how they use it. In contrast, mere theory-driven visualisation of components and their relationships is not helpful and effective for enhancing process control performance. It is suggested that simulator training have experts be involved in the preparation of knowledge maps for the presentation of theoretical knowledge. With regard to temporal and adaptive transfer and to the usefulness of cognitive maps for the target group, the studies give little information.

\subsubsection{Situated learning methods}

\subsubsection{Guided discovery.}

Description of method. In guided discovery, trainees discover important aspects of the task themselves. The instructor selects those learning tasks in which trainees can discover selected system relationships on their own. Guided discovery is squarely predicated on the activity of the trainee, who has to look actively for relationships between system variables and interpret them.

Research evidence. In several experiments, guided discovery led to a solid knowledge base and good control performance (Haider 1992, Vollmeyer and Burns 1996, Vollmeyer et al. 1996), although only on less complex simulation tasks compared to highly complex control tasks with only a few coupled subsystems. Kluge (2007) showed that the benefits of guided discovery disappeared with increasing task complexity.

Utility for simulator training. Considering the members of the target group and their prior experience in the plants, the demand on the acquisition of declarative and procedural knowledge and task complexity, guided discovery is recommended to be useful for simulator training with generic or basic-principles simulators, which are less complex and detailed than full-scope simulators. The expectation, especially in the basic training courses, is that guided discovery can enhance the knowledge and rule acquisition of 
the trainees. The usefulness of guided discovery for temporal and adaptive transfer is still unclear.

\subsubsection{Error training.}

Description of method. Salas et al. (2006) define error training as a technique that "promotes learning through trainees experiencing errors, seeing the consequences of such errors, and receiving feedback' (p. 484). According to Salas et al. (2006), error training must encompass four elements: error occurrence; error correction; self-correction; supported correction. Some variations of error training emphasise the emotional learning objectives by helping trainees monitor and control their negative emotions, such as frustration when errors are made (Bell 2002).

Research evidence. The success of error training depends very much on the amount and quality of guidance and assistance given to the learners. Guided error-training in combination with supported correction proved to be superior for skill development (Lorenzet et al. 2003). Guiding trainees into and out of errors leads to better performance and increased self-efficacy on their part than avoiding errors during training. Rather than a practice of just letting trainees make errors, calculated instruction in error management is needed to foster short- and medium-term transfer (Heimbeck et al. 2003). The overall effectiveness of error-management training was confirmed by a meta-analysis, which found a medium effect size ( $d=0.44$; Keith and Frese 2005). The effect size increased when one of the following moderators was present: (a) communication of clear and unequivocal feedback; (b) measurement of test performance rather than of training performance; or (c) existence of adaptive transfer (Ivancic and Hesketh 2000).

Utility for simulator training. Error training has so far been used only for computer software and driving tasks, which are rather simple compared to process control tasks. With regard to the acquisition of declarative and procedural knowledge, two aspects need to be considered for simulator use: (a) the subject matter experts should define beforehand which common errors the trainees make; (b) learning from errors is possible if there is clear feedback that learners can interpret. Given the target group's work experience, it could be helpful to distinguish between novice and expert learners. Error training can be helpful to novices during their work with a generic simulator. For experts participating in a followup course, the full-scope simulator can be used because these learners are expected to have a more elaborate mental model that helps them interpret even complex feedback cues. With regard to temporal and adaptive transfer, error training facilitates both.

\subsubsection{Social-cognitive learning}

\subsubsection{Knowledge-based training.}

Description of method. Knowledge-based training (sometimes also called 'system-based training' or 'guidance in the use of system knowledge') is intended to equip the operator with a deep understanding of the system and to aid fault-finding and fault-fixing. This kind of training involves teaching the trainee about interdependencies and interactions of system parameters and system components (e.g. the fact that increasing tank pressure affects gas temperature) and giving room for imitation of procedures and 
maintenance rules. It also includes knowledge about the boundaries of the system (e.g. the fact that tank pressure must not exceed 50 bar).

Research evidence. In a qualitative analysis of the effectiveness of training methods, knowledge-based training was identified as one of the most effective training methods for dealing with the multiple demands of industrial process control (Morris and Rouse 1985). In particular, when operators are confronted with novel faults (faults requiring a flexible response with no established procedures to rely on), knowledge-based training proved to be rather effective (Patrick and Haines 1988, Hockey et al. 2007). With regard to temporal transfer, there is some evidence that skill retention after lay-off periods is better with knowledge-based than with rule-based training (see below, Sauer et al. 2000).

Utility for simulator training. The evidence in the research literature suggests that knowledge-based training is an appropriate approach that may represent an important element in the acquisition of declarative knowledge and procedural skills through simulator training. With regard to adaptive transfer, knowledge-based training is effective because it instils considerable flexibility into the operator's range of strategies, allowing for an adaptable response to deal with unfamiliar operational scenarios. Temporal transfer may also be supported (e.g. through the use of checklists and handbooks), but the evidence is not as strong for adaptive transfer.

\subsubsection{Cognitive apprenticeship.}

Description of method. Cognitive apprenticeship (Collins et al. 1989) makes use of an experienced operator who talks aloud during problem-solving. As in the first phases in Bandura's social-cognitive learning (Bandura 1986), the trainee observes the problemsolving steps explicitly described and verbalised by the expert. This approach combines principles and features of the traditional craft apprenticeship with elements of cognitive training.

Research evidence. Schaper and Sonntag (1998) combined cognitive apprenticeship with concept mapping to teach knowledge and strategies (rules) by experts for a training period of 6 weeks. They reported that cognitive apprenticeship and mapping had a positive impact on individual performance. Both methods support knowledge transfer from experts to novices.

Arthur et al. (1997) used an active interlocked modelling technique, which is defined as 'observational learning in the context of actively performing a task in harmony with a partner' who serves as a model (Arthur et al. 1997, p. 784). The active interlocked modelling technique 'requires trainees to perform each half of a task alternately with a partner who performs the other half' (p. 784). Arthur et al. (1997) showed that the dyadic training method led to results as good as those achieved by individual training. This finding is interesting because the trainees in the active interlocked modelling conditions had only half as much direct practice as the trainees in the individual condition.

Utility for simulator training. With regard to the acquisition of declarative knowledge and procedural skills, the simulation trainer should support learning by modelling the 
important steps once before the trainees themselves complete the required steps by using the simulator. By verbalising the steps, the rules, the reasons for them and the expected consequences, trainees can learn through observation and can link the needed knowledge to each step. This approach's usefulness to the target group and to temporal and adaptive transfer has not yet been investigated.

\subsubsection{Rule-based training.}

Description of method. The aim of this training method is to teach operators a set of procedures that allows them to deal with a range of disruptions in the system. The premise is that following these step-by-step guidelines is an efficient way of managing the system.

Research evidence. There is considerable evidence for the effectiveness of this training method. In a review by Morris and Rouse (1985), procedure-based training (which in their classification system is called guidance in the use of algorithms or rules) emerged as one of the most effective training methods. Rule-based training, which is less sensitive to physical stressors such as noise, requires few cognitive resources because it has been shown to be particularly effective under difficult operational conditions (Hockey et al. 2007).

Utility for simulator trainings. The research evidence appears to show that rule-based training is a method suitable for simulator training. It may be particularly useful for practising stressful emergency situations (e.g. system failure that threatens human lives). Its obvious limitation is that it is only applicable in situations that have been anticipated by the system designer. This method may be less effective for both temporal transfer (because extended lay-off periods may pose a problem for skill maintenance) and adaptive transfer (e.g. procedures may be too inflexible to be applied to novel situations).

\subsubsection{Part-task training.}

Description of method. Part-task training is defined as 'practice on some set of components of a whole task as a prelude to practice of or performance of the whole task' (Wightman and Lintern 1985, p. 267). In part-task training, trainees are not confronted with the full complexity of the task right from the beginning. Instead, trainees practise various separate components of the full task. At the end of the training phase, the separately practised parts are reintegrated to accomplish the whole task. Four main approaches within part-task training are distinguished (Stammers 1980, Wightman and Lintern 1985, Gopher et al. 1989): segmentation; fractionation; simplification; emphasis-shift training. Segmentation entails the isolation of distinct temporal or spatial segments. Fractionation breaks down the whole task into elements that have to be executed simultaneously. Simplification implies the reduction of difficulty on one or more elements of the task. Emphasis-shift training deconstructs a whole task according to the relative emphasis (priority) of selected components and leaves the whole task intact.

Research evidence. Segmentation procedures such as backward chaining proved to be the most effective part-task methods (Wightman and Lintern 1985). Fractionation was less effective than whole-task training and simplification resulted in positive transfer but was generally not superior to whole-task training. Emphasis-shift training that introduced 
systematic changes in the emphasis on subcomponents resulted in significant advantages over alternative training methods, such as traditional part-task and whole-task training (Gopher et al. 1989).

Utility for simulator training. With regard to procedural knowledge that needs to be acquired, most of the procedural tasks within process control oblige strict conformance to a fixed schema and specified action steps. Part-task training is highly recommended for this purpose. According to the empirical evidence presented, it would lead to a backwardchaining part-task method, which might be very unusual for trainers and trainees. Nonetheless, it should be considered for further research. In contrast, the emphasis-shift method has proved to support the learning of complex tasks. All part-task training methods are developed for the initial acquisition of knowledge and skills and should therefore be most effective in the basic courses. Nevertheless, not much is known about the temporal and adaptive transfer potential of part-task training and its acceptance by experienced operators.

\subsubsection{Drill and practice.}

Description of method. Drill and practice mean repetitive work on a task until a certain proficiency level is reached. Merrill (2001) emphasises that active practice is the single most neglected aspect of instruction. Results reported by Colquitt et al. (2000) strongly support the principle holding that acquired procedural skills are the best predictor for transfer performance.

Research evidence. Morris and Rouse (1985), Foss et al. (1989), Mattoon (1994) and Kontogiannis and Shepherd (1999) summarised that practice improves performance best. In general, Hagman and Rose (1983) concluded that retention can be enhanced by increasing the amount of training through task repetition and that repetitions are effective when applied both before and after task proficiency has been achieved. The problem seems to be that practice raises only control performance; it does not affect the amount of acquired knowledge (e.g. Kamouri et al. 1986, Funke and Müller 1988, Putz-Osterloh et al. 1988, Wallach 1996). Therefore, practice should be combined with exposure to structure diagrams, as shown by Kluwe (1996) and Preussler (1998).

Utility for simulator training. Drill and practice mainly support the acquisition of procedural skills and promote temporal transfer. Research suggests that practice sessions should be more systematically integrated into the simulator training courses than they currently are. In common practice as revealed by the interviews, the controlled systems are slow to respond. Most of the checklists and procedures are talked through only once. But in cases of important procedures or frequently made mistakes, continuous practice is needed and should be considered. Less is known about the usefulness of drill and practice for adaptive transfer and their suitability for the target group.

\subsubsection{Overlearning.}

Description of method. Overlearning refers to the deliberate overtraining in a task after the learner has reached a set criterion (Driskell et al. 1992). Overlearning is a prolongation of 
drill and practice and is particularly important for tasks that need to become highly automated.

Research evidence. A meta-analysis revealed that overlearning has a significant moderate overall effect independent of task type and retention interval (Driskell et al. 1992). The effects of overlearning are stronger for cognitive tasks than for physical tasks. However, overlearning itself is affected by task issues (e.g. number of performance steps required by the task), ability issues (e.g. general mental abilities; see Hagman and Rose 1983) and different forgetting curves and rates of skill loss (O'Hara 1990). A 50\% overlearning manipulation should be considered a minimum practical operationalisation of overlearning and small improvements in performance can be expected from this level of training. But in terms of costs and effectiveness, $100 \%$ overtraining achieved better results than $50 \%$ overlearning in introductory training and $50 \%$ overlearning in mid-term followup training (Schendel and Hagman 1982).

Utility for simulator training. Cognitive procedural skills appear highly susceptible to the effects of forgetting, especially when contrasted with continuous control skills (Fleishman and Parker 1962, Schendel and Hagman 1982, Farr 1987, Arthur et al. 1998, Ginzburg and Dar-El 2000). Cognitive procedural skills therefore need overlearning. Considering the advantages that overlearning has for the acquisition of procedural knowledge and for temporal transfer, there is a need to intensify emphasis on the procedural and control aspects of a task rather than on its psychomotor and automatic elements. (Use of written checklists is recommended as well.) The important procedural training issues should be overlearned, at least in the basic courses. According to the research results reviewed in this article, initial overlearning is a good predictor of skill maintenance and should be stressed in basic courses more than is currently the case. But further research is needed to replicate the findings, which stem from environments and tasks with relatively low complexity. As with drill and practice, there has been no investigation into whether overlearning is useful for supporting adaptive transfer and the acquisition of declarative knowledge among experienced learners.

\section{Implications and outlook}

The goal of this paper has been to examine the issue of training design for process control simulators. The field study shows that some aspects of current training practices vary considerably, mainly as a function of simulator type, training theories and legal constraints. In contrast, similar practices were observed across organisations with regard to the target groups in training and the distinction between basic and follow-up courses.

The review of available training methods leads to the conclusion that not all the methods that were examined appear to be equally appropriate for simulator training, particularly with regard to promoting temporal and adaptive transfer. The methods that are proposed as the most promising ones for further empirical research are error training, rule-based training, knowledge-based training, cognitive apprenticeship, drill and practice, overlearning and guided discovery. 
Drawing on the literature review and the field study, the following suggestions are made, which can strengthen the empirical foundation for the design of simulator training and for further research:

- Most studies on the design of training exist in domains other than industrial process control and emphasise laboratory-based research with low-complexity tasks. The most promising training methods need to be evaluated with regard to their effectiveness in a process control environment.

- In particular, the evaluation of the training methods should address the question of their utility for temporal and adaptive transfer. Very few studies have dealt with these two specific criteria of training effectiveness.

- The training methods need to be evaluated separately with regard to their utility for basic and follow-up courses. In the training studies reviewed, this distinction has hardly been made. The matter is strongly related to the question of temporal transfer outlined above (e.g. retention of skills acquired in basic courses determines the timing of follow-up courses).

- The evaluation of training methods for experienced operators may have to be conducted separately from those for less experienced operators.

- There is a need to evaluate both the sequencing of the different training methods and their share of training total time for the best combination. Combining different methods is likely to be superior to relying on one best method alone. This aspect of training evaluation should be tackled in the final stages of the evaluation process.

To some extent, the research proposed may draw on laboratory-based work if, as advocated, that work has incorporated task scenarios more complex than those used thus far. The scaled world research paradigm (Schifflet et al. 2004) would be one possible approach. Such laboratory-based work may serve as an initial test of the effectiveness of the training methods before an attempt is made to validate these in a high-fidelity simulator.

Driven by the availability of increasingly powerful computer technology, the use of simulators for training purposes is likely to grow. It is thus urgent to address the issues raised in this article, which it is hoped will help establish a research agenda to guide future empirical work on the design of simulator training in process control environments.

\section{Acknowledgement}

This project is funded by the Swiss National Science Foundation.

\section{References}

Amico, V. and Clymer, A.B., eds., 1984. All about simulators. La Jolla, CA: Society for Computer Simulation.

Arthur, W., et al., 1997. Dyadic versus individual training protocols: loss and reacquisition of a complex skill. Journal of Applied Psychology, 82, 783-791.

Arthur, W., et al., 1998. Factors that influence skill decay and retention: a quantitative review and analysis. Human Performance, 11 (1), 57-101.

Bandura, A., ed., 1986. Social foundations of thought and action. A social cognitive theory. Englewood Cliffs, NJ: Prentice-Hall. 
Bell, B.S., 2002. An examination of the instructional, motivational, and emotional elements of error training. Thesis (PhD). Michigan State University.

Berry, D.C. and Broadbent, D.E., 1984. On the relationship between task performance and associated verbalisable knowledge. Quarterly Journal of Experimental Psychology, 36, 209-231.

Cobb, P. and Bowers, J., 1999. Cognitive and situated learning perspectives in theory and practice. Educational Researcher, 28, 4-15.

Collins, A., Brown, J.S., and Newman, E., 1989. Cognitive apprenticeship: teaching the crafts of reading, writing and mathematics. In: L.B. Resnick, ed. Knowing, learning and instruction. Hillsdale, NJ: Lawrence Erlbaum Associates Inc., 453-494.

Colquitt, J.A., LePine, J.A., and Noe, R.A., 2000. Toward an integrative theory of training motivation: a meta-analytic path analysis of 20 years of research. Journal of Applied Psychology, 85, 678-707.

Crossman, E.R. and Cooke, J.E., 1974. Manual control of slow-response systems. In: E. Edwards and F.P. Lees, eds. The human operator in process control. London: Taylor \& Francis, 51-66.

Driskell, J.E., Willis, R.P., and Copper, C., 1992. Effect of overlearning on retention. Journal of Applied Psychology, 77, 615-622.

Farr, M.J., ed., 1987. The long-term retention of knowledge and skills. New York: Springer.

Fleishman, E. and Parker, J., 1962. Factors in the retention and relearning of perceptual-motor skill. Journal of Experimental Psychology, 64 (3), 215-226.

Flexman, R.E. and Stark, E.A., 1987. Training simulators. In: G. Salvendy, ed. Handbook of human factors. New York: Wiley, 1012-1038.

Foss, M.A., et al., 1989. Unsupervised practice: the performance of the control group. Acta Psychologica, 71, 23-51.

Frischknecht, A., and Deutschmann, H., (1995). Simulator-training - Aspekte der Aufsichtsbehörde [Simulator training - the perspective of the supervisory authority]. In: Schweizerische Vereinigung für Atomenergie, eds. Simulatoren für die Ausbildung der Kernkraftwerkspersonals. Bern: SVA, 1.3-1-1.3-13.

Funke, J. and Müller, H., 1988. Eingreifen und Prognostizieren als Determinanten von Systemidentifikation und Systemsteuerung [Entering inputs and making predictions as determinants of system identification and controling]. Sprache \& Kognition, 7, 176-186.

Ginzburg, S. and Dar-El, E.M., 2000. Skill retention and relearning - a proposed cyclical model. Journal of Workplace Learning, 12, 327-332.

Gopher, D., Weil, M., and Siegel, D., 1989. Practice under changing priorities: an approach to the training of complex skills. Acta Psychologica, 71, 147-177.

Greeno, J.G., Smith, D.R., and Moore, J.L., 1993. Transfer of situated learning. In: D.K. Dettermann and R.J. Sternberg, eds. Transfer on trial: intelligence, cognition, and instruction. Norwood, NJ: Ablex, 99-167.

Hagman, J.D. and Rose, A.M., 1983. Retention of military tasks: a review. Human Factors, 25, 199-213.

Haider, H., 1992. Implizites Wissen und Lernen. Ein Artefakt? [Implicit knowledge and learning. An artefact? ${ }^{\sim}$. Zeitschrift für experimentelle und angewandte Psychologie, 39, 68-100.

Heimbeck, D., et al., 2003. Integrating errors into the training process: The function of error management instructions and the role of goal orientation. Personnel Psychology, 56, 333-361.

Heineken, E., et al., 1992. Strategien des Denkens bei der Regelung eines einfachen dynamischen Systems unter verschiedenen Totzeitbedingungen [Thinking strategies to control a simple dynamic system under different conditions of feedback delay]. Sprache \& Kognition, 11, 136-148.

Heintzman, R.J., 1984. Flight simulation: history, evaluation, and future directions. In: V. Amico and A.B. Clymer, eds. All about simulators. La Jolla, CA: Society for Computer Simulation, 170-175.

Hockey, G., Sauer, J., and Wastell, D.G., 2007. Adaptability of training in simulated process control: knowledge- versus rule-based guidance under task changes and environmental stress. Human Factors, 49, 158-174. 
International Atomic Energy Agency, 1996. Nuclear power plant personnel training and its evaluation. A guidebook. Technical Reports Series, no. 380. [Vienna: IAEA].

International Atomic Energy Agency, 2004. Use of control room simulators for training of nuclear power plant personnel. Vienna: IAEA, IAEA-TECDOC-1411.

Ivancic, K. and Hesketh, K., 2000. Learning from error in a driving simulation: effects on driving skill and self-confidence. Ergonomics, 43, 1966-1984.

Jonassen, D.H., Beimer, K., and Yacci, M., 1993. Structural knowledge: techniques for representing, conveying, and acquiring structural knowledge. Hillsdale, NJ: Lawrence Erlbaum Associates Inc.

Kamouri, A.L., Kamouri, J., and Smith, K.H., 1986. Training by exploration: facilitating the transfer of procedural knowledge through analogical reasoning. International Journal of ManMachine Studies, 24, 171-192.

Keith, N. and Frese, M., 2005. Performance effects of error management training: a meta-analysis. In: 20th Annual Conference of the Society for Industrial and Organizational Psychology, Los Angeles, CA, USA.

Kieras, D.E. and Bovair, S., 1984. The role of a mental model in learning to operate a device. Cognitive Science, 8, 255-273.

Kluge. A., 2007. Experiential learning methods, simulation complexity and their effects on different target groups. Journal of Educational Computing Research, 36 (3), 323-349.

Kluwe, R.H., 1996. Effects of type of learning on control performance. In: D. Harris, ed. Engineering psychology and cognitive ergonomics. Aldershot: Ashgate, 81-88.

Kontogiannis, T. and Shepherd, A., 1999. Training conditions and strategic aspects of skill transfer in a simulated process control task. Human-Computer Interaction, 14, 355-393.

Kragt, H. and Landeweerd, J.A., 1974. Mental skills in process control. In: E. Edwards and F.P. Lees, eds. The human operator in process control. London: Taylor \& Francis, 135-145.

Lorenzet, S., Salas, E., and Tannenbaum, S.I., 2003. Benefiting from mistakes: the impact of guided errors on learning, performance and self-efficacy. Human Resource Development Quarterly, 16, 301-322.

Mattoon, J.S., 1994. Designing instructional simulations: effects of instructional control and type of training task on display-interpretation skills. The International Journal of Aviation Psychology, 4, 189-209.

Merrill, M.D., 2001. First principles of instruction. Journal for Structural Learning and Intelligent Systems, 14, 459-466.

Morris, N.M. and Rouse, W.B., 1985. Review and evaluation of empirical research in troubleshooting. Human Factors, 27, 503-530.

O'Hara, J.M., 1990. The retention of skills acquired through simulator-based training. Ergonomics, $33,1143-1153$.

Ormerod, T.C. and Shepherd, A., 2004. Using task analysis for information requirements specification: The SGT method. In: D. Diaper and N. Stanton, eds. The handbook of task analysis for human-computer interaction. London: Lawrence Erlbaum Associates, 347-366.

Patrick, J. and Haines, H., 1988. Training and transfer of fault-finding skills. Ergonomics, 31, 193-210.

Preussler, W., 1998. Strukturwissen als Voraussetzung für die Steuerung komplexer dynamischer Systeme [Structural knowledge as a prerequisite to control complex and dynamic systems]. Zeitschrift für Experimentelle Psychologie, 45, 218-240.

Putz-Osterloh, W., Bott, B., and Houben, I., 1988. Beeinflusst Wissen über ein realitätsnahes System dessen Steuerung? [Does knowledge influence the control of a 'real-life' system?]. Sprache \& Kognition, 10, 240-251.

Rasmussen, J., 1997. Risk management in a dynamic society: a modelling problem. Safety Science, 27, 183-213.

Salas, E., Bowers, C.A., and Rhodenizer, L., 1998. It is not how much you have but how you use it: toward a rational use of simulation to support aviation training. The International Journal of Aviation Psychology, 8, 197-208. 
Salas, E., et al., 2006. Design, delivery, and evaluation of training systems. In: G. Salvendy, ed. Handbook of human factors and ergonomics. Hoboken, NJ: Wiley and Sons, 472-512.

Sauer, J., Hockey, G.R., and Wastell, D.G., 2000. Effects of training on short- and long-term skill retention in a complex multiple-task environment. Ergonomics, 43, 2043-2064.

Schaper, N., 1997. Strukturlegetechniken zur Förderung von Wissenserwerb und -anwendung bei beruflichen Aufgaben in modernen Arbeitsstrukturen. In: G. Richardt, G. Krampen and H. Zayer, eds. Beiträge zur Angewandten Psychologie. Bonn, Germany: Deutscher Psychologen Verlag, 423-426.

Schaper, N. and Sonntag, K., 1998. Analysis and training of diagnostic expertise in complex technical domains. European Journal of Work and Organizational Psychology, 7, 479-498.

Schendel, J.D. and Hagman, J.D., 1982. On sustaining procedural skills over a prolonged retention interval. Journal of Applied Psychology, 67, 605-610.

Schifflet, S.G., et al., eds., 2004. Scaled worlds: development, validation, and applications. Aldershot: Ashgate Publishing Limited.

Schneider, W., 1985. Training high-performance skills: fallacies and guidelines. In: R.W. Swezey and D.H. Andrews, eds. Readings in training and simulation: a 30-year perspective. Santa Monica, CA: Human Factors and Ergonomics Society, Reprint from Human Factors, 27, 285-300.

Stammers, R.B., 1980. Part and whole practice for a tracking task: effects of task variables and amount of practice. Perceptual and Motor Skills, 50, 203-210.

Stammers, R.B., 1996. Training issues. In: N. Stanton, ed. Human factors in nuclear safety. London: Taylor \& Francis, 189-196.

Vicente, K.J., 2006. The human factor. Revolutionizing the way people live with technology. New York: Routledge.

Vicente, K.J. and Rasmussen, J., 1990. The ecology of human-machine systems II: mediating 'direct perception' in complex work domains. Ecological Psychology, 2, 207-249.

Vicente, K.J., Roth, E.M., and Mumaw, R.J., 2001. How do operators monitor a complex, dynamic work domain? The impact of control room technology. International Journal of HumanComputer Studies, 54, 831-856.

Vollmeyer, R. and Burns, B., 1996. Hypotheseninstruktion und Zielspezifität: Bedingungen, die das Erleben und Kontrollieren eines komplexen Systems beeinflussen [Instruction based on hypothesis and goal specificity: conditions that influence the experience and control of complex system]. Zeitschrift für Experimentelle Psychologie, 43, 657-683.

Vollmeyer, R., Burns, B.D., and Holyoak, K.J., 1996. The impact of goal specificity on strategy use and the acquisition of problem structure. Cognitive Science, 20, 75-100.

Waibel, E., \& Benkert, J., 1995. KKW-Ausbidungssimulatoren - Übersicht und Einführung [Training simulators for nuclear power plants - Overview and introduction]. In: Schweizerische Vereinigung für Atomenergie, eds. Simulatoren für die Ausbildung der Kernkraftwerkspersonals. Bern: SVA, 1.1-1-1.1-10.

Wallach, D., 1996. Learning to control a coal-fired power plant: empirical results and a model. In: D. Harris, ed. Engineering psychology and cognitive ergonomics, vol. 2, Job design and product design. Aldershot: Ashgate, 89-96.

Weick, K.E. and Sutcliffe, K.M., 2003. Das unerwartete managen. San Francisco: Jossey-Bass.

Wickens, C.D., ed., 1992. Engineering psychology and human performance, 2nd ed. New York: Harper Collins Publishers Inc.

Wightman, D.C. and Lintern, G., 1985. Part-task training for tracking and manual control. Human Factors, 27, 267-283.

\footnotetext{
About the authors

Annette Kluge is Assistant Professor for I/O psychology at the University of St Gallen, Switzerland. She studied I/O psychology at the Technical University Aachen, Germany, and obtained her Doctorate in ergonomics and vocational training at the University of Kassel, Germany in 1994. Her research topics are
} 
simulator-based human factor research and safety culture in high reliability organisations, training research, crew resource management training in aviation and non-aviation industries and organisational learning from errors.

Jürgen Sauer is Associate Professor of cognitive ergonomics at the Department of Psychology, University of Fribourg, Switzerland. He obtained his PhD from the University of Hull, UK, in 1997 and an MSc in occupational psychology from the University of Sheffield, UK, in 1990. His main research interests are in the field of automation, training, team work, stress and the design of consumer products. He is a member of the editorial board of Ergonomics.

Kerstin Schüler is research assistant for I/O psychology at the University of St. Gallen. She earned her Diploma in psychology at the University of Freiburg im Breisgau, Germany. Her research interests include e-learning, instructional design and personnel development in profit, and non-profit organisations.

Dina Burkolter is research assistant for I/O psychology at the University of St. Gallen. She earned her lic. phil. in psychology at the University of Zurich, Switzerland. Her research interests include cognitive requirement analysis, operator training for process control tasks and situation awareness training. 